\title{
SURGICAL APPROACH IN CONGENITAL LONG QT INTERVAL SYNDROME PATIENTS
}

\author{
Diāna Stoldere, Elīna Cimbolineca \\ Riga Stradins University, Faculty of Residency
}

\begin{abstract}
Summary
Long QT syndrome is a genetically determined clinical condition that can lead to sudden cardiac death, life-threatening arrhythmias, typically ventricular tachycardia - Torsades de Pointes in young, otherwise healthy, adults and children.

Congenital long QT syndrome is the most common cause of sudden death in young adults with structurally normal heart.

There are several studies, which introduce us to gene mutation types, responsible for this disease. At this point 17 types of LQTS gene mutations are recognized, most patients present with the first 3 LQTS gene mutations: KCNQ1, KCNH2, and SCN5A. Secondary factors like electrolyte disbalance, dietary restrictions, and specific drugs may also cause QT interval prolongation. It is important to rule out avoidable causes, before further evaluation of congenital disease.

Several treatment options are used in daily practice, which also includes a surgical approach.

Although not so often used and seen, surgical technique has positive results - recognized by both doctors and patients.

Keywords: long QT syndrome, left cardiac sympathetic denervation, LQTS
\end{abstract}

\section{INTRODUCTION}

Congenital long QT syndrome (LQTS) is a genetic disorder, which presents with ion channel dysfunction and clinically is characterized by syncope/seizures, lifethreatening arrhythmia's, and sudden cardiac death in young adults $(1,2)$.

There are no specific symptoms, that can specifically lead healthcare professionals to diagnose LQTS from the start, only a high level of suspicion may indicate in the right direction. For such a tool, that may lead us to the correct diagnosis is Schwartz score.

LQTS prevalence varies from $1 / 2000-1 / 2500$ in live births, in different studies $(3,2)$.

Congenital LQTS is caused by 17 different gene mutations (Table 1), that result in prolongation of QT interval, seen in ECG $(4,5)$.

Important to highlight that - new mutations are disclosed very dynamically, also literature tells us, in about $10-15 \%$ of LQTS cases the exact mutation isn't found, at the same time other causes of QT prolongation are ruled out as well (30).

Prolongation of QT interval indicates prolonged heart repolarization, that can lead to ventricular tachycardia Torsades de Pointes (TdP), ventricular fibrillation and sudden death.

\section{ECG analysis}

Lead II, V5 and V6 of a 12-lead ECG, is used for QT interval measurments (6). To evaluate actual length of QT interval, mathematically calculated value of corrected QT (QTc) is used in a daily practice. The "borderline" that indicate QT interval prolongation is $440 \mathrm{~ms}$, but $>450 \mathrm{~ms}$ in men and $>460 \mathrm{~ms}$ in women is defined as QT interval prolongation. In pediatric populations, QTc $>460 \mathrm{~ms}$, from 1 to 15 years, will be considered as QT interval prolongation $(6,7)$.
Treatment of this syndrome varies from clinical presentation, level of risk for sudden cardiac death, genetical profile, and family history.

Treatment options are: lifestyle modifications, pharmacological treatment, implantation of implantable cardioverter-defibrillator (ICD), surgical left cardiac sympathectomy $(8,9)$.

\section{Genetical variations}

Congenital long QT syndrome is associated with mutations in sodium, potassium, and calcium channels. Mutations in all of the channels above damage the repolarization of cardiomyocytes in different phases, but leading to the same result - prolongation of QT interval. According to recent researches, we now know 17 genes and $~ 600$ mutations of them, which is associated with congenital long QT syndrome. These genes, chromosomal locus, their inheritance, and effect to ion channels are shown in Table 1.

Three most common LQTS mutations appear in KCNQ1, KCNH2 and SCN5A genes - also the first three types of LQTS matches with these genes (10). Mutations of these genes, affects up to $80 \%$ of LQTS patients (5).

Congenital long QT syndrome, type 1 (LQT1)

Most common of all the LQTS types, affects up to $30-$ $35 \%$ of LQTS patients. The mutation is detected in KCNQ1 gene - it causes the impaired activity of Iks potassium channel, leading to inhibition of potassium ione outflux out of the cardiomyocyte. The outcome of these changes is prolonged repolarization (1).

Type specific triggers: usually arrhythmias are triggered by adrenergic stimulation, for example, exercise, especially swimming (10). 
Congenital long QT syndrome, type 2 (LQT2)

The prevalence of this type reaches up to $25-30 \%$ out of all LQTS patients. In the case of type 2 LQTS, channel activity changes are seen in potassium Ikr channel - retardation of its action leads to high levels of potassium intracellularly. The level of potassium maintains high cellular resting potential, therefore repolarization is prolonged as well ( 1 ).

Type specific triggers: are sudden auditory stimuli, for example, alarm clock, doors slamming shut or telephone ringing (11)

\section{Congenital long QT syndrome, type 3 (LQT3)}

The widespread presence of LQT3 is $5-10 \%$ in the congenital LQTS patient group. Type 3 characterizes mutation, found in the SCN5A gene. Changes that happen in sodium INa channel action are an increase of the channel activity, resulting in higher levels of sodium in cardiomyocyte during the Plato phase. Because of the high sodium level intracellularly during this phase, repolarization is prolonged (1).

Type specific triggers: patients are at risk to have a cardiac event when their heart rate is slower, for example, during sleep (10).

\section{Other causes of QT prolongation}

Patients with QTc prolongation in ECG must be evaluated for some other causes, which may imitate the congenital LQTS. The first step always is to exclude preventable causes, followed by screening for congenital syndrome if there is no evidence for other objective origins.

QTc prolongation may provoke:

- Various drugs (antidepressants, antifungal agents, some antiarrhythmic drugs, antibiotics, and others - homepage: www.crediblemeds.org)

- Disbalance of electrolyte levels: hypokalaemia, hypomagnesaemia, hypocalcemia

- Neurological diseases, for example, subarachnoid hemorrhage

- Congenital heart disease

- Dietary restrictions - in patients with anorexia nervosa

- $\quad$ Thyroid diseases - high levels of thyroid hormones may provoke QTc prolongation

- Also, predisposition for long QTc is in patients with hypertension, left ventricular hypertrophy, diabetes mellitus, high cholesterol level, in women, in older patients - risk increase with age, ischemia of the myocardium $(31,32)$

\section{Lifestyle modifications}

All of the congenital LQTS patients with no exceptions corresponding to age, gender, or the LQTS type must follow certain non-pharmacological treatment recommendations. It is important to understand that all of the reasons above that may cause acquired QTc prolongation, also have an impact on patients with congenital LQTS, leading to the same result.

Education.Patients must be educated about drugs, which may have a QTc prolonging effect. The daily usage of these medications needs to be restricted as much as possible. Otherwise, it may lead to sudden cardiac events. If there is no other choice, close monitoring may follow.

An important aspect is electrolyte level changes, which can impact the QT interval. Essential potassium, magnesium, and calcium level changes, for example, happen during infectious gastroenteric diseases diarrhea, vomiting, and fever. The cardiac events may develop if electrolyte disbalance is not corrected properly.

Limitations of physical activity. Activities are recommended for LQTS patients at a level of daily activity. According to the American Heart Association/American Cardiac Society expert consensus statement 2015, LQTS patients are allowed to perform various types of sports, and even take part in competitions, if there is a known plan for action in a situation of a cardiac event, and AED ( automated external defibrillator) is available. But, the European Society of Cardiology is strict - patients are not recommended to take part in competitions, for the reason of high cardiac event risk.

Patients also are recommended to avoid genomespecific triggers - swimming, loud noises, sudden emotional stress corresponding to the type of LQTS $(13,33,34,35)$.

\section{Recommendations for Long QT syndrome non-surgical treatment.}

Most common therapeutic tactic is unselective betablocker (for example, Propranololum or Nadololum) prescription.

Beta-blocker activity overwhelms adrenergic stimulation, preventing syncope or development of ventricular tachycardia (5).

Beta-blockers are used in various cases - in asymptomatic, in clinically symptomatic patients. Medical therapy can be started in patients with normal QTc range, but genetically positive congenital LQTS. 36 Beta-blocker therapy is initiated in patients with resting QTc greater than $470 \mathrm{~ms}$, but with resting QTc less than $470 \mathrm{~ms}$, a beta-blockers can be recommended $(4,14)$.

Effectivity of beta-blocker therapy has been proved in clinical studies - cardiovascular events raise from 0.31 case/per year/ per patient, receiving therapy, to 0.97 events/ per year/ per patient without therapy (36) The greatest effect from beta-blockers shows type 1 LQTS patients, as well as type 2 and 3 LQTS patients results, suggest a positive effect (37).

For high-risk patients developing cardiac events or symptomatic patients despite $\beta$-blocker treatment - ICD implantation or left cardiac sympathetic denervation are indicated (14)

Indications for ICD implantation are:

- $\quad$ patients after surviving sudden cardiac death or

- $\quad$ episodes of syncope while receiving therapy with $\beta$-blockers or

- $\quad$ QTc interval is $>550 \mathrm{~ms}$ (17). 
Surgical approach - left cardiac sympathectomy (LCS)

Surgical approach - left cardiac sympathectomy - has been known for a long period, first reports coming from 1971 (4). At this point this surgery has a very limited list of indications, used for the treatment of congenital ventricular arrhythmias, following:

- Long QT syndrome

- Catecholaminergic polymorphic ventricular tachycardia, (5)

in clinical situations, listed below:

1. intolerance to $\beta$ - blocker therapy,

2. high risk of sudden death, despite received treatment,

3. contraindications for ICD implantation or frequent shocks,

4. also, there are reports of LCS use for bridging to ICD implantation (6).

The LCS strategy is reasonable, because of the pathogenetic mechanism of cardiac events - they are provoked by hyperstimulation of sympathetic nervous system, manifesting as known clinics of LQTS (7)

According to Heart Rhythm Society, European Heart Rhythm Association and Asia Pacific Heart Rhythm Society - HRS/EHRA/APHRS - expert consensus statement recommends LCS for LQTS patients, in whom ICD therapy is contraindicated or patient refuses it, and/ or beta blockers therapy is unsuccessful - ineffective, contraindicated, badly tolerated (18).

It is important to admit that only a small number of centers apply this surgical strategy.

LCS provides positive results - procedure decreases cardiac events in LQTS patients in the level of ICD activity, improving patient's quality of life (17)

Over the years there have been several surgical techniques to provide LCS. The first technique, that was developed for LCS, was left stellectomy (19), this procedure indicated ablation of left stellate ganglion. Unfortunately, this procedure clinically shows low effect on cardiac events, although, at the time of technical development, studies proved complete cardiac sympathetic denervation in animals (7), and also left stellectomy complicates with Horner's syndrome $(20,6)$. Horner syndrome manifests with triade: partial ptosis, miosis and anhidrosis, on the side of lost sympathetic innervation from Stellate ganglion to the oculus. However, it is not recommended to use left stellectomy, due to only partial effect on human heart and high risk for complications.

The left cervicothoracic sympathectomy - is improved version of left stellectomy. During this procedure, left stellate ganglion is resected, accompanied by first $2-4$ thoracic ganglions, thus resulting in cervicothoracic sympathetic denervation, that provides alphaadrenergic inhibition of the heart (21). It provides a significant long-term positive outcome such as aborted cardiac arrests, syncope, but it does not completely suppress risk for sudden cardiac death (22), procedure may also increase the risk of developing Horner syndrome and hemidiaphragmatic paralysis.10 Risk of developing Horner's syndrome persists of the ocular sympathetic fiber route - they intersect the upper portion of the ganglion (7). Left cervicothoracic sympathectomy improves gain of benefits regarding to the primary problem - sympathetic activity, but meanwhile is accompanied by Horner syndrome in a lot of cases.

The high thoracic left sympathectomy (HTLS) offers removal of the lower half of stellate ganglion accompanied by the first $4-5$ left thoracic ganglia. This approach provides good alpha-adrenergic inhibition of the heart and is associated with a lower incidence of Horner syndrome than previous surgeries. As mentioned before, ocular sympathetic fibers cross the upper part of the ganglion, thus risk of Horner's syndrome development is reduced. Most of the studies recommend HTLS as first line in need for LCS, regarding to better cardiac effect and lower level of complications $(20,9)$. HTLS can be performed conventionally or thoracoscopically, described further. The conventional procedure is usually performed by supraclavicular extrapleural approach. Experienced centres describe the duration of this surgery as $35-40$ minutes long.

Steps of the procedure:

1. At the site of the incision - at the left supraclavicular area - small incision is made

2. Followed by retraction of n.phrenicus and m. scaleni anterior

3. Next - lig. pleurae is redistributed

4. And last: Stellate ganglion, along with first $4-5$ thoracic ganglions are separated and detached (6)

Procedure can also be performed by video-assisted thoracoscopy (VATS), reffering to a minimally invasive approach $(23,24)$.

VATS approach of HTLS:

1. Left lung isolation ( double lumen endotracheal tube or bronchial blocker) are required to perform the HTLS procedure.

2. Patient is positioned in partial lateral decubitus position.

3. Three small incisions are made in the left side of the chest: at the level of third ( for the camera), fourth ( for a grasper or retractor), fifth ( for the electrocautery hook dissector) intercostal space along the linea axillaris media

4. After that, follows structure identifying - for orienteering.

5. Forthcoming: pleural incision - medial to the heads of the ribs

6. Next: identification of left sympathetic ganglion chain.

7. Followed by sympathectomy, using electrocautery, of the stellate ganglion lower part $+\mathrm{T} 1$ to $\mathrm{T} 4 / \mathrm{T} 5$ ganglions.

VATS allows shorter hospital stays than conventional surgical techniques and minimal perioperative complications compared to conventional approach (20). 


\section{MATERIALS AND METHODS}

We selected clinical reports, that included patients with congenital LQTS recieving LCS therapy, using the PubMed database. A search was performed using keywords - LQTS and surgical therapy, sympathectomy, left cardiac sympathetic denervation (LCSD).

A total number of 5 studies were included in further analysis, according to this literature review. Exclusion criteria were: unavailability to the full article, patients with acquired LQTS. A summary of the reviewed papers is shown in Table 2 .

\section{LCS outcomes in clinical practice - clinical report analysis}

The procedure is rarely used in daily practice. Occurrences of these procedures may be affected by the genetic adherence of the main disease - LQTS, because it will influence the treatment options in every single case, and recommended indications.

A surgical approach is never the first choice of LQTS treatment plan. It is the next step after other treatment options have failed. Table 2 shows that in most of the cases it is an effective treatment method and should always be kept as an option for patients who are possible candidates for it.

Patients, who underwent LCSD, mostly belong to pediatric population or young adult group. Reviewed studies show not only clinical improvement in cardiac events (26), but also patient satisfaction with surgical treatment and relief of symptoms that have a significant impact on quality of life $(27,29)$.

Mostly there were no significant changes in QTc interval, except Haranal et al study. All of the studies below recognize the use and effectiveness of so-called LCSD therapy.

\section{DISCUSSION}

Patient management with congenital channelopathies is quite challenging.

First of all - the path to the correct diagnosis. There are known several reasons, mentioned before, that may provoke QTc prolongation. A clinician with a high level of suspicion can lead to this correct pathway. Other clinical states may mimic LQTS. Before assuming the diagnosis of LQTS patients, they must undergo several examinations, clinical consultations, and tests.

Next, is the tactics of therapy. Or even when do we start some kind of medical, device, or surgical treatment? There are several LQTS patients without any cardiac events, meanwhile, there are ones, who face these events daily. Guidelines recommend us one or other tactics, but sometimes all the answers can't be found there. Clinical experience also is very valuable in this kind of disease.

The surgical approach is as effective as medical treatment, but it is not the first choice (18). Betablockers have proven effectiveness even in patients without QTc prolongation but genetically inherited LQTS (36). Next step after unsuccessful treatment with beta-blockers is ICD implantation, according to guidelines (18). But effectiveness is similar in both ICD and LCSD. Both options come with some kind of risks and/or side - effects. LCSD may be a more invasive procedure than ICD implantation, and also less used. Maybe a lack of experience in this technique is the basis of LCSD non - use. Very few centers have experience with LCSD, like all techniques, this also must be performed enough to use. During times - the development of the LCSD technique may influence the use of it, knowing the side - effects of left stellectomy. Maybe this knowledge does not allow us to confide in this approach.

LCSD may be considered in symptomatic patients without response to adequate treatment with betablockers (18).

\section{CONCLUSIONS}

Results of surgical approach show a significant impact on LQTS patients' clinical status changes and improvement in quality of life. LCSD treatment is an effective and important option for LQTS patients. In symptomatic patients these procedures show important enhancement. Therefore LCSD may be considered more often in symptomatic patients.

\section{Conflict of interest: None}

Table 1 Gene mutations

\begin{tabular}{|c|c|c|c|c|}
\hline & Gene & Locus & Functional effect & $\begin{array}{c}\text { Mode of } \\
\text { inheritance }\end{array}$ \\
\hline LQT1 & KCNQ1 & $11 \mathrm{p} 15.5$ & $\downarrow \mathrm{I}_{\mathrm{Ks}}$ & $\mathrm{AD} / \mathrm{AR}$ \\
\hline LQT2 & KCNH2 & $7 \mathrm{q} 35-46$ & $\downarrow \mathrm{I}_{\mathrm{Kr}}$ & $\mathrm{AD}$ \\
\hline LQT3 & SCN5A & $3 \mathrm{p} 21-\mathrm{p} 2$ & $\uparrow \mathrm{I}_{\mathrm{Na}}$ & $\mathrm{AD}$ \\
\hline LQT4 & ANK2 & $4 \mathrm{q} 25-\mathrm{q} 27$ & $\begin{array}{c}\text { Multichannel } \\
\text { interactions }\end{array}$ & $\mathrm{AD}$ \\
\hline LQT5 & KCNE1 & $21 \mathrm{q} 22.1$ & $\downarrow \mathrm{I}_{\mathrm{Ks}}$ & $\mathrm{AD}$ \\
\hline LQT6 & KCNE2 & $21 \mathrm{q} 22.1$ & $\downarrow \mathrm{I}_{\mathrm{Kr}}$ & $\mathrm{AD}$ \\
\hline LQT7 & KCNJ2 & $17 \mathrm{q} 23$ & $\downarrow \mathrm{I}_{\mathrm{K} 1}$ & Sporadic \\
\hline LQT8 & CACNA1C & $2 \mathrm{p} 13.3$ & $\uparrow \mathrm{I}_{\mathrm{Ca}}$ & $\mathrm{AD}$ \\
\hline LQT9 & CAV3 & $3 \mathrm{p} 25$ & $\uparrow \mathrm{I}_{\mathrm{Na}}$ & $\mathrm{AD}$ \\
\hline LQT10 & SCN4B & $11 \mathrm{q} 23.3$ & $\uparrow \mathrm{I}_{\mathrm{Na}}$ & $\mathrm{AD}$ \\
\hline LQT11 & AKAP9 & $7 \mathrm{q} 21-\mathrm{q} 2$ & $\downarrow \mathrm{I}_{\mathrm{Ks}}$ & $\mathrm{AD}$ \\
\hline LQT12 & SNTA1 & $20 \mathrm{q} 11.2$ & $\uparrow \mathrm{I}_{\mathrm{Na}}$ & $\mathrm{AD}$ \\
\hline LQT13 & KCNJ5 & $11 \mathrm{q} 24$ & Reduced $\mathrm{I}_{\mathrm{KACh}}$ & $\mathrm{AD}$ \\
\hline LQT14 & CALM1 & $14 \mathrm{q} 24-\mathrm{q} 31$ & Increase I $_{\mathrm{CaL}}$ & Sporadic \\
\hline LQT15 & CALM2 & $2 \mathrm{p} 21$ & Increase I $_{\mathrm{Ca}}$ & Sporadic \\
\hline LQT16 & CALM3 & $19 \mathrm{q} 13$ & Likely increase $_{\mathrm{Cal}}$ & Sporadic \\
\hline LQT17 & TRDN & - & $\uparrow \mathrm{I}_{\mathrm{CaL}}$ & - \\
\hline 2 & & & \\
\hline
\end{tabular}

$(2,3)$ 
Table 2 Summary of clinical reports - LQTS patients, who underwent surgical treatment

\begin{tabular}{|c|c|c|c|c|c|c|}
\hline Reference & $\begin{array}{l}\text { Number } \\
\text { of patients } \\
(N)\end{array}$ & $\begin{array}{l}\text { Mean } \\
\text { /median } \\
\text { age } \\
\text { (years) }\end{array}$ & Procedure & $\begin{array}{l}\text { Clinical } \\
\text { improvement }\end{array}$ & $\begin{array}{l}\text { QTc interval } \\
\text { changes } \\
\text { before }(B) \\
\text { and after }(A) \\
\text { procedure, } \\
\text { ms }\end{array}$ & Study conclusion \\
\hline $\begin{array}{l}\text { Costello et } \\
\text { al (8) }\end{array}$ & 8 & $\begin{array}{l}\text { Median } \\
\text { age } 13\end{array}$ & $\begin{array}{l}\text { Partial stellate } \\
\text { ganglion } \\
\text { and T2 - T5 } \\
\text { sympath- } \\
\text { ectomy }\end{array}$ & $\begin{array}{l}\text { In } 88 \% \text { of } \\
\text { patients, } \\
\text { symptoms were } \\
\text { reduced }\end{array}$ & $\begin{array}{l}\text { B median } \\
465(439- \\
564) \\
\\
\text { A median } \\
460(428- \\
562)\end{array}$ & $\begin{array}{l}\text { Useful treatment } \\
\text { strategy via VATS } \\
\text { for LQTS patients }\end{array}$ \\
\hline $\begin{array}{l}\text { Jang et al } \\
(9)\end{array}$ & 14 & $\begin{array}{l}\text { Mean } \\
24.6 \pm \\
10.5\end{array}$ & VATS - LCSD & $\begin{array}{l}\text { Cardiac event } \\
\text { rates decreased } \\
\text { from } 0.97 \text { to } \\
0.19 \text { events/ } \\
\text { year }(\mathrm{P}=0.045) \\
\text { in symptomatic } \\
\text { patients }\end{array}$ & $\begin{array}{l}\text { B } 594.1 \pm \\
70.0 \\
\text { A } 578.8 \pm \\
69.3 \\
p=0.470\end{array}$ & $\begin{array}{l}\text { LCSD is effective } \\
\text { procedure }\end{array}$ \\
\hline $\begin{array}{l}\text { Waddell- } \\
\text { Smith et al } \\
\text { (10) with } \\
\text { a median } \\
\text { follow-up of } \\
29 \text { months } \\
\text { (range, } 1-67 \\
\text { months }\end{array}$ & 40 & $\begin{array}{l}\text { Median } \\
\text { age } 17\end{array}$ & $\begin{array}{l}\text { VATS - LCSD, } \\
\text { resection } \\
\text { degree variable } \\
\text { among patients }\end{array}$ & $\begin{array}{l}5 \% \text { experienced } \\
\text { cardiac events } \\
\text { after procedure. } \\
53 \% \text { were } \\
\text { symptomatic } \\
\text { before (including } \\
7 \text { CPVT patients) }\end{array}$ & $\begin{array}{l}\text { B } 461 \pm 60 \\
\text { A } 476 \pm 54 \\
p=0.49\end{array}$ & $\begin{array}{l}\text { Patients had } \\
\text { high levels of } \\
\text { postoperative } \\
\text { satisfaction. }\end{array}$ \\
\hline $\begin{array}{l}\text { Hwang et al } \\
\text { (11) }\end{array}$ & 1 & $11 \pm 0$ & VATS - LCSD & $\begin{array}{l}\text { Six month follow- } \\
\text { up without cardiac } \\
\text { events }\end{array}$ & No data & $\begin{array}{l}\text { LCSD is safe and } \\
\text { effective method }\end{array}$ \\
\hline $\begin{array}{l}\text { Haranal et al } \\
(12)\end{array}$ & 5 & \begin{tabular}{|l|}
$31.25 \pm$ \\
13.12 \\
years \\
(study also \\
included \\
$C P V T, P V T$, \\
$V T)$
\end{tabular} & VATS - HTLS & \begin{tabular}{|l|} 
Significant \\
symptomatic relief \\
in all patients
\end{tabular} & $\begin{array}{l}\text { B } 661 \pm \\
39.39 \\
\text { A } 462 \pm \\
51.67\end{array}$ & $\begin{array}{l}\text { Effective } \\
\text { therapeutical } \\
\text { method, with } \\
\text { significant results }\end{array}$ \\
\hline Total & 68 & & & & & \\
\hline
\end{tabular}

LQTS - long QT syndrome, VATS - video-assisted thoracoscopy, LCSD - left cardiac sympathetic denervation, CPVT catecholaminergic polymorphic ventricular tachycardia, PVT - polymorphic ventricular tachycardia, VT - ventricular tachycardia, HTLS - high thoracic left sympathectomy 


\section{REFERENCES}

1. Bohnen MS, Peng G, Robey SH, et al. Molecular Pathophysiology of Congenital Long QT Syndrome. Physiol Rev. 2017;97(1):89-134. doi:10.1152/ physrev.00008.2016

2. Van Niekerk C, Van Deventer BS, Du Toit-Prinsloo L. Long QT syndrome and sudden unexpected infant death. J Clin Pathol. 2017;70(9):808-813. doi:10.1136/jclinpath-2016-204199

3. Schwartz PJ, Stramba-Badiale M, Crotti L, et al. Prevalence of the congenital long-QT syndrome. Circulation. 2009;120(18):1761-1767. doi:10.1161/ CIRCULATIONAHA.109.863209

4. Neira V, Enriquez A, Simpson C, Baranchuk A. Update on long QT syndrome. J Cardiovasc Electrophysiol. 2019. doi:10.1111/jce.14227

5. Wallace E, Howard L, Liu M, et al. Long QT Syndrome: Genetics and Future Perspective. Pediatr Cardiol. 2019;40(7):1419-1430. doi:10.1007/ s00246-019-02151-X

6. Antonopoulos A, Lawrence D, Patrini D, et al. The role of sympathectomy in long QT syndrome. $J$ Thorac Dis. 2017;9(9):3394-3397. doi:10.21037/ jtd.2017.08.45

7. Johnson JN, Ackerman MJ. QTc: how long is too long? Br J Sports Med. 2009;43(9):657-662. doi:10.1136/bjsm.2008.054734

8. Cardiac Health. Long QT Syndrome (Figuur). Card Heal. 2017:1524-1529. doi:10.1161/ CIRCULATIONAHA.113.003985

9. Schwartz PJ, Crotti L, Insolia R. Long-QT syndrome from genetics to management. Circ Arrhythmia Electrophysiol. 2012;5(4):868-877. doi:10.1161/ CIRCEP.111.962019

10. Shah M, Carter C. Long QT syndrome: A therapeutic challenge. Ann Pediatr Cardiol. 2008;1(1):18-26. doi:10.4103/0974-2069.41051

11. Manuscript A. NIH Public Access. 2010;7(12):18061807. doi:10.1016/j.hrthm.2010.09.075.Editorial

12. Gepstein L, Boulous M. Specific Therapy Based on the Genotype in a Malignant Form of Long QT3, Carrying the V4l1M Mutation. 2019:979-982. doi:10.1536/ihj.18-705

13. Priori SG, Blomstrom-Lundqvist C, Mazzanti A, et al. 2015 ESC Guidelines for the management of patients with ventricular arrhythmias and the prevention of sudden cardiac death the Task Force for the Management of Patients with Ventricular Arrhythmias and the Prevention of Sudden Cardiac Death of the European Society of Cardiology (ESC) Endorsed by: Association for European Paediatric and Congenital Cardiology (AEPC). Eur Heart J. 2015;36(41):2793-2867l. doi:10.1093/eurheartj/ ehv316

14. Callans DJ. 2017 AHA / ACC / HRS Guideline for Management of Patients With Ventricular Arrhythmias and the Prevention of Sudden Cardiac Death : Executive Summary. 2018;72(14). doi:10.1016/j.jacc.2017.10.053

15. Chockalingam P, Crotti L, Girardengo G, et al. Not All Beta-Blockers Are Equal in the
Management of Long QT Syndrome Types 1 and 2 Higher Recurrence of Events Under Metoprolol. JAC. 2012;60(20):2092-2099. doi:10.1016/j. jacc.2012.07.046

16. Mazzanti A, Maragna R, Vacanti G, et al. Interplay Between Genetic Substrate, QTc Duration, and Arrhythmia Risk in Patients With Long QT Syndrome. J Am Coll Cardiol. 2018;7 ( 15):1663 LP 1671. doi:10.1016/j.jacc.2018.01.078

17. Cho Y. Management of Patients with Long QT Syndrome. Korean Circ J. 2016;46(6):747-752. doi:10.4070/kcj.2016.46.6.747

18. Priori SG, Salvatore Maugeri F, Wilde AA, et al. HRS/EHRA/APHRS Expert Consensus Statement on the Diagnosis and Management of Patients with Inherited Primary Arrhythmia Syndromes STATES Representative for American College of Cardiology Representative for American Heart Association Representative for Pediatric and Congenital Electrophysiology Society * Representative for Association for European Pediatric and Congenital Cardiology. 2013. https://www.escardio.org/static_ file/Escardio/Press-media/press-releases/2013/ diagnosis-management-patients-inheritedprimary-arrhythmia-syndromes.pdf.

19. Coyer BH, Pryor R, Kirsch WM, Blount SG. Left stellectomy in the long QT syndrome. Chest. 1978;74(5):584-586. doi:10.1378/chest.74.5.584

20. Cho Y. Left cardiac sympathetic denervation: An important treatment option for patients with hereditary ventricular arrhythmias. $J$ arrhythmia. 2016;32(5):340-343. doi:10.1016/j. joa.2015.08.002

21. Wung PK, Wigley FM. Sympathectomy Learn more about Sympathectomy Management of Systemic Sclerosis and Raynaud's Phenomenon RAYNAUD PHENOMENON AND VA- SOMOTOR SYNDROMES Raynaud Phenomenon and Vasomotor Syndromes. 2017.

22. Bos JM, Bos KM, Johnson JN, Moir C, Ackerman MJ. Left cardiac sympathetic denervation in long QT syndrome: Analysis of therapeutic nonresponders. Circ Arrhythmia Electrophysiol. 2013;6(4):705-711. doi:10.1161/CIRCEP.113.000102

23. Téllez LJ, Garzón JC, Vinck EE, Castellanos JD. Video-assisted thoracoscopic cardiac denervation of refractory ventricular arrhythmias and electrical storms: a single-center series. J Cardiothorac Surg. 2019;14(1):17. doi:10.1186/s13019-019-0838-6

24. Schwartz PJ, Priori SG, Cerrone M, et al. Left Cardiac Sympathetic Denervation in the Management of High-Risk Patients Affected by the Long-QT Syndrome. Circulation. 2004;109(15):1826-1833. doi:10.1161/01.CIR.0000125523.14403.1E

25. Costello JP, Wilson JK, Louis C, et al. Surgical cardiac denervation therapy for treatment of congenital ion channelopathies in pediatric patients: a contemporary, single institutional experience. World J Pediatr Congenit Heart Surg. 2015;6(1):33-38. doi:http://dx.doi.org/10.1177/2150135114555203 
26. Jang SY, Cho Y, Kim NK, et al. Video-Assisted Thoracoscopic Left Cardiac Sympathetic Denervation in Patients with Hereditary Ventricular Arrhythmias. PACE - Pacing Clin Electrophysiol. 2017;40(3):232-241. doi:10.1111/pace.13008

27. Waddell-Smith KE, Ertresvaag KN, Li J, et al. Physical and Psychological Consequences of Left Cardiac Sympathetic Denervation in Long-QT Syndrome and Catecholaminergic Polymorphic Ventricular Tachycardia. Circ Arrhythmia Electrophysiol. 2015;8(5):1151-1158. doi:10.1161/ CIRCEP.115.003159

28. Hwang SW, Thomas JG, Whitehead WE, et al. Left thorascopic sympathectomy for refractory long QT syndrome in children. $J$ Neurosurg Pediatr PED. 2011;8(5):455-459. doi:10.3171/2011.8.PEDS 11164

29. Haranal MY, Simha P, Shenthar J, Rajasekharappa R. High thoracic left sympathectomy for recalcitrant ventricular tachyarrhythmias and long QT syndrome. Indian J Thorac Cardiovasc Surg. 2018;34(2):103-108. doi:10.1007/s12055-0170548-4

30. Ackerman, M. J. \& Schwartz, P. J. Congenital long QT syndrome: Pathophysiology and genetics. UpTo Date 1-29 (2019).

31. Van Noord, C., Eijgelsheim, M. \& Stricker, B. H. C. Drug- and non-drug-associated QT interval prolongation. Br. J. Clin. Pharmacol. 70, 16-23 (2010).

32. Northrup H, Koenig MK, Pearson DA, Au KS. Long QT Syndrome. 2018:1-36. https://www.ncbi.nlm. nih.gov/books/.

33. A. Pelliccia et al., "Recommendations for competitive sports participation in athletes with cardiovascular disease: A consensus document from the Study Group of Sports Cardiology of the Working Group of Cardiac Rehabilitation and Exercise Physiology and the Working Group of My," Eur. Heart J., vol. 26, no. 14, pp. 1422-1445, 2005.
34. D. J. Tester, P. J. Schwartz, and M. J. Ackerman, “Congenital long QT syndrome," Electr. Dis. Hear. Vol. 1 Basic Found. Prim. Electr. Dis., pp. 439-468, 2013.

35. M. J. Ackerman, D. P. Zipes, R. J. Kovacs, and B. J. Maron, “Eligibility and Disqualification Recommendations for Competitive Athletes with Cardiovascular Abnormalities: Task Force 10: The Cardiac Channelopathies: A Scientific Statement from the American Heart Association and American College of Cardiology," J. Am. Coll. Cardiol., vol. 66, no. 21, pp. 2424-2428, 2015.

36. A. J. Moss et al., "Effectiveness and limitations of $\beta$-blocker therapy in congenital long- QT syndrome," Circulation, vol. 101, no. 6, pp. 616$623,2000$.

37. A. Barsheshet, O. Dotsenko, and I. Goldenberg, "Genotype-specific risk stratification and management of patients with long QT syndrome," Ann. Noninvasive Electrocardiol., vol. 18, no. 6, pp. 499-509, 2013.

\section{Address:}

Diāna Stoldere

Faculty of Medicine

Riga Stradiņš University

16 Dzirciema street

Riga, Latvia LV - 1007

e-mail: diana.stoldere@gmail.com 